\title{
TEORÍA DE SISTEMAS, FUNCIONES DEL DERECHO Y CONTROL SOCIAL. Perspectivas e imposibilidades para la dogmática penal
}

\author{
Evaristo Prieto Navarro \\ Universidad Autónoma de Madrid
}

\section{Una introducción polémica}

En los últimos tiempos, la dogmática penal y las teorías del control que desde ella se postulan han sufrido una drástica transformación. A las finalidades clásicas de control del comportamiento, que se cifraban en la intimidación de cara a las presumibles conductas infractoras (prevención general negativa) se añaden otros efectos sociales de carácter más exigente y de intención más profunda. Así, las llamadas teorías de la prevención general positiva o «prevención-integración» resaltan que la pena afirma la vigencia del Derecho como mecanismo regulador de las conductas y lo restablece en su calidad de tal ante las amenazas que el delito trae consigo e incluso, más allá, que la pena actuaría como mecanismo de conformación de la conciencia jurídica colectiva, dado que su aplicación restablece al cabo la confianza y la fidelidad del ciudadano a la norma jurídica ${ }^{1}$.

La nueva comprensión que se gesta de las funciones del Derecho penal, y de los rendimientos potenciales que la pena alberga de cara a la prevención de conductas y la reparación de los daños que el delito trae consigo, no queda reducida a este ámbito jurídico. La reelaboración de las posibilidades de la pena y de la idea del control que a esta técnica social se adhieren sugiere asímismo una nueva asociación entre ciencia jurídica y ciencia social general, allende las formas en que tradicionalmente esta colaboración ha venido adoptando. Superado el primitivismo teórico que las dogmáticas penales tradicionales traicionaban, parece abrirse un nuevo espacio de encuentro con las últimas elaboraciones de la sociología, que habrían de aportar una mejor pintura de las realidades sociales de las que las normas parten, y a las que al

${ }^{1}$ Debo manifestar mi deuda con el libro de Mercedes Pérez Manzano Culpabilidad y Prevención. Las teorías de la prevención general positiva en la fundamentación de la imputación subjetiva y de la pena. Madrid, Ediciones de la UAM, 1990, por su valiosas observaciones sobre los fundamentos y alcance de las teorías penales de la prevención general positiva. 
cabo revierten, junto con una más ajustada percepción de las virtualidades que los mecanismos de control punitivo podrían tentativamente alentar.

En el arsenal de teorías y visiones de la realidad social que se prestan al diálogo, llama a la atención especialmente la vigorosa apuesta que la mejor dogmática penal actual ha hecho por la teoría de sistemas. Es cuando menos llamativo el hecho de que la ciencia penal se haya decantado por un planteamiento tan exigente y radical en sus miras e intenciones, y tan equívoco y ambiguo en sus posibilidades y resultados. La fuerte contestación con que la teoría de sistemas ha sido recibida en los ambientes académicos, hace que la sombra de la sospecha contamine a todo enfoque disciplinar que trate de movilizar sus instrumentos e intuiciones conceptuales en provecho propio. No otra cosa sucede con la teoría de la prevención general positiva, en parte, justo es admitirlo, como consecuencia de su peculiar visión de la realidad de la pena, el delito y el funcionamiento de los mecanismos penales como estrategias de control de la conducta, pero también, en gran medida, a consecuencia de las amistades teóricas con las que va de la mano, y que constituirían su fundamento conceptual, metodológico, y hasta epistémico.

El abanico de las dudas y perplejidades se abre, pues, originariamente, en la teoría de sistemas, sobre todo a propósito de su formulación podría decirse que «canónica», en la obra de Niklas Luhmann². Pasaremos revista a algunas de estas críticas, y trataremos de desentrañar la raíz del malestar que planteamientos como el de Luhmann provocan. Pero, igualmente, apuntaremos a otras causas del malestar teórico que actualmente embarga a la ciencia jurídica penal, que no se reconducen sin esfuerzo al empleo cabal de la teoría de sistemas, sino a motivos que han de apuntarse inequívocamente en su haber profesional. Pues las dudas que la prevención general positiva plantea alcanzan a la recepción particular que ha venido practicando de la teoría de Luhmann, no siempre justificable, y por lo que en ella no es en modo alguno sistémico, pese a las seducciones terminológicas que pudieran inducir a aceptar lo contrario.

La objeción sobre la legitimidad y posibilidades de la recepción de la teoría de sistemas alcanza a tres aspectos. En primer lugar, albergo dudas más que

${ }^{2}$ Otras manifestaciones o, mejor dicho, abiertas reelaboraciones de la teoría de sistemas, consiguen bordear algunos de los inconvenientes que la crítica plantea, pero al precio de sacrificar la coherencia, el poder explicativo y el aliento teórico ambicioso del planteamiento de Luhmann. Entre estos intentos derivados merecen especial atención los que salen de la pluma de Günther Teubner y Helmut Willke, en relación con el ámbito del Derecho. No puede ocultarse, por mor de la coherencia, que las hibridaciones, al tiempo que se liberan de estrecheces y corsés conceptuales tan rigurosos como los que acompañan a Luhmann, dejan un regusto oportunista francamente incómodo. Es la sensación que embarga a los que leemos las propuestas de estos dos autores a propósito de las posibilidades de control que las herramientas jurídicas pueden pretender. 
indiciarias sobre la supuesta fidelidad con que las tesis de Luhmann han sido acogidas en la ciencia del Derecho penal. No objeto que las teorías puedan ser extrapoladas con intención abiertamente instrumental, siempre que la violencia de tal traslación no las desfigure hasta tornarlas irreconocibles. Esto se ve agravado cuando se pretende mantener la filiación teórica estricta al original sistémico más allá de la metáfora casual y puede que feliz en su efecto retórico. Conviene prestar atención al hecho de que ciertos conceptos, hipótesis y métodos de trabajo poseen un inequívoco parecido de familia con la teoría de sistemas, y que sólo desde el interior de este planteamiento alcanzarían su sentido más reconocible y fructífero. Urge pues, por todo lo apuntado, esclarecer el sentido y alcance de las categorías aparentemente sistémicas en el seno de la prevención general positiva, dando cuenta de sus posibilidades, o imposibilidades, de su alcance y sus limitaciones, de sus promesas y rendiciones anticipadas.

Al hilo de lo anterior, y esa sería la segunda de mis objeciones, conviene llamar la atención de que algunas de las propuestas funcionales de la prevención general positiva, que se han identificado como inequívocamente sistémicas en su aliento por parte de los críticos, no lo son, o al menos, no pueden reconocerse como estrictamente sistémicas a la luz del último giro que la teoría de Luhmann emprendió desde principios de los ochenta (Derecho como sistema autopoiético). Tras estos planteamientos dogmáticos habrá que sospechar otros parentescos menos patentes, que autores como Müller-Tuckfeld, ya se han ocupado de ventilar de modo convincente ${ }^{3}$. No estarían, en esta línea, en la intención teórica de Luhmann las funciones, adscritas a la pena, de protección de la integridad del ordenamiento, de la fidelidad expresada hacia el mismo, o de refuerzo de la conciencia normativa que el delito ha puesto en peligro. Los presupuestos teóricos de partida del planteamiento sistémico lastran gravemente la posibilidad de apuntar tales posibilidades en su haber funcional.

En tercer lugar, no puedo ocultar mi descreimiento sobre las posibilidades que, de modo entusiasta, los partidarios de la prevención general positiva creen entrever, para la dogmática penal, en el enfoque ya sí estrictamente luhmaniano. Lejos de ello, creo que las predecisiones teóricas y con-

\footnotetext{
${ }^{3}$ Müller-Tuckfeld, en su obra Integrationsprävention. Studien su einer Theorie der gesellschaftichen Funktion des Strafrechts. Frankfurt, Peter Lang, 1998, subraya la conexión inequívocamente durkheimiana de la teoría de la prevención general positiva. Cualquier lector mínimamente atento de La División del Trabajo Social coincidirá con este autor en que algunas funciones, como el refuerzo de la conciencia normativa y la identidad social generada por el Derecho se retrotraen al sociólogo francés. Notoria es igualmente la adscripción hegeliana, admitida por Jakobs y expuesta con claridad y concisión en la obra de Heiko H.Lesch La Función de la Pena. Madrid, Dykinson, 1999.
} 
ceptuales, metodológicas, epistémicas, y hasta ontológicas, que vertebran la propuesta de interpretación de la realidad de la teoría de Luhmann, perjudican decisiva e irremisiblemente las posibilidades de construir una teoría del control tan exigente como la que ofrece el enfoque de la prevención general positiva.

Caso de perseverar en la apuesta por este planteamiento dogmático-penal, habríamos de buscar una fuente de inspiración y préstamo bien diferente. Y en el supuesto de querer mantenerse del lado de las teorías de Luhmann, nos veríamos forzados a concebir un modelo bien distinto de relación entre el sistema jurídico, el sistema social y los individuos - o sistemas psíquicos, en la terminología de Luhmann. La reivindicación perseverante en los planteamientos sólo presuntamente sistémicos de la teoría de la prevención general positiva nos conduce, consecuentemente, allende las intenciones originarias del planteamiento de Luhmann. Tal insistencia obcecada en las posibilidades constructivas de esta teoría nos urgiría a buscar una versión tan modificada de ésta, tan revisada y maltrecha por las necesarias deformaciones estructurales a que habría de someterse, que la harían enteramente irreconocible.

\section{El Derecho como sistema autopoiético. Posibilidades y limitaciones}

\subsection{La función del Derecho. Código y clausura operativa}

La categoría básica de la función nos sitúa ante la referencia que todo sistema diferenciado guarda con relación a un problema social global. Su centralidad se refuerza a la luz del papel sistemático que está llamada a desempeñar en la reflexión de Luhmann. La función explica, en primer término, la emergencia de un sistema diferenciado de comunicaciones en el seno de la sociedad como sistema general y omniabarcante. Se atribuye en exclusiva a este sistema, y es, al tiempo, el fundamento de la reproducción de las operaciones (comunicaciones) del mismo. La clausura operativa de los sistemas sociales, lo que Luhmann denomina su autopoiesis, se cimenta precisamente sobre el cumplimiento cabal de la función asignada.

En el caso de los sistemas sociales, tomados genéricamente, la clausura operativa tiene lugar sobre el expediente de las comunicaciones. También Jakobs hace suya esta intuición, cuando entiende que el Derecho penal no es sino un sistema de comunicaciones, y que la pena misma no es sino una comunicación que resulta cualificada en atención a un servicio funcional determinado ${ }^{4}$. La clausura operativa nos indica, por el momento, que sólo

${ }^{4}$ Jakobs plantea una teoría comunicacional de la pena. Así, en la pág. 18 de su libro Sociedad, norma y persona en una teoría de un Derecho penal funcional. Madrid, Civitas, 1996. 
las comunicaciones integran el contenido y se incorporan a la reproducción de los sistemas sociales, que no puede hablarse rectamente de aportes externos a la hora de plantear el funcionamiento de los sistemas. Tal clausura obra también en el seno de cada uno de los sistemas sociales que se diferencian funcionalmente: Derecho, sistema económico, sistema educativo, sistema de la ciencia, etcétera. El Derecho, por su parte, se estructura como sistema de comunicaciones que atiende a la función de protección de expectativas normativas de conducta.

La función de garantía de expectativas normativas, que Luhmann atribuye al sistema jurídico, es lo que explica su emergencia, lo que enraiza su carácter propio y necesario, y lo que explica la exclusividad y autonomía que detenta el Derecho en el cumplimiento de su tarea. Pues la función privativa de cualquiera de los sistemas no puede ser cumplida por otros sistemas diferentes, ni siquiera en parte. No hay, pues, garantía alguna de mantenimiento de expectativas al margen de la cobertura que extiende el ordenamiento jurídico. Toda vez que las comunicaciones sociales que las expectativas normativas representan ingresan en el ámbito del Derecho, son procesadas y respondidas en el interior del Derecho. La expectativa es reconocida y amparada en el interior del sistema jurídico, y su tratamiento, de principio a fin, y todas las comunicaciones que a ella se asocian, tienen lugar únicamente aquende los límites del Derecho.

Las expectativas que protege el Derecho son las que denominamos normativas, frente a las que Luhmann llama cognitivas ${ }^{5}$. Las expectativas normativas son aquéllas que han de ser mantenidas incólumes ante la decepción que pueden sufrir eventualmente a manos de una realidad que a menudo les es refractaria. Esperamos algo normativamente cuando ante la aparación de la frustración, de la contradicción de los hechos, podemos seguir legítimamente manteniéndonos en la validez de nuestra expectativa, sabiendo que contamos con el respaldo institucional a tal acto de resistencia. La normatividad no es otra cosa que contrafacticidad, susceptibilidad de no aprendizaje ante la falta de ajuste con la realidad, frente a la cognitividad, que favorece y hasta demanda un estilo abierto al aprendizaje de lo nuevo. Como puede bien intuirse, la normatividad, con su estilo refractario y cerrado ante las realidades, se compadece bien con la clausura autopoiética propia del sistema jurídico. El Derecho puede así entenderse como un orden continuo de reproducción de comunicaciones normativas, que se asocian recursivamente sin poner en peligro su carácter contrafáctico.

\footnotetext{
${ }^{5}$ Sobre las expectativas, deben consultarse el artículo «Normen in soziologischer Perspektive», en Soziale Welt, 20, 1, 1969, págs. 28-48, y su ya clásico Rechtssoziologie, Opladen, Westdeutscher Verlag, $3^{\mathrm{a}} \mathrm{ed}, 1987$, págs. 40-53.
} 
También el código jurídico ${ }^{6}$ nos sitúa en la misma línea de consideraciones. El código es una simplificación que los sistemas ponen a su base para agilizar el funcionamiento de su autopoiesis, la recursividad de sus comunicaciones propias. Es al mismo tiempo una retícula de observación y construcción de las realidades: cada sistema modaliza la infinitud de referencias posibles de sentido de acuerdo a una distinción originaria, que marca su ámbito privado de existencia y pone en marcha su autopoiesis. La unidad de los sistemas, en este sentido, se fundamenta en una distinción ${ }^{7}$, que sirve al tiempo como criterio de pertenencia de las comunicaciones en torno a las que se conforma. En el caso del Derecho, el código fundador es el que discierne lo jurídico de lo antijurídico (Recht-Unrecht). Todas las comunicaciones sobre expectativas normativas (dimensión funcional o sustancial de delimitación del sistema) han de adherirse, para su elaboración a uno de los dos polos del código. Y a partir de ellos, comienza la historia propia de la interacción, y se van confirmando y condensando cursos particulares, que a su vez pasan a sedimentarse en la memoria propia del sistema, en sus estructuras o programas. La dogmática ${ }^{8}$, sin ir más lejos, cumple su cometido precisamente en la garantía de la continuidad de las asociaciones que se vinculan a determinadas comunicaciones del sistema jurídico, en la necesaria continuidad que ha de prestarse a la recursión de operaciones a lo largo del tiempo. En el mismo tenor, la justicia ${ }^{9}$ no es para Luhmann algo distinto de esa igualdad de tratamiento que ha de preservarse ante las potenciales mutaciones que el entorno social experimenta.

\subsection{Clausura y apertura. Posibilidades e imposibilidades de contacto entre sistemas.}

La clausura operativa en torno a la función y el código no conllevan, sin embargo, la negación de la apertura del sistema de referencia con relación a su medio. La autopoiesis afecta sólo a la operación, y no a cualquier posibilidad de observar el entorno y acoger esta percepción como base de posteriores reelaboraciones internas de sentido. La clausura, paradójicamente,

${ }^{6}$ Sobre código y función, «Codierung und Programmierung», en Das Recht der Gesellschaft, Frankfurt, Suhrkamp, 1993, págs. 165-214. Asímismo, «Die Codierung des Rechtssystems», en Rechtstheorie, 17 (1986), págs. 171-203.

${ }^{7}$ «Unidad como diferencia». Véase, «Die Einheit des Rechtssystems», en Rechtstheorie 14 (1983), págs. 129-154.

${ }^{8}$ Luhmann consagra al papel social de la dogmática su libro Sistema jurídico y Dogmática jurídica, Madrid, Centro de Estudios Constitucionales, 1983.

9 «Gerechtigkeit in den Rechtssystemen der modernen Gesellschaft», en Ausdifferenzierung des Rechts, Frankfurt, Suhrkamp, 1981, págs. 374-418, y «Kontingenzformel Gerechtigkeit», en Das Recht der Gesellschaft, op.cit. págs. 214-238. 
no perjudica la apertura, sino que la hace posible. Esto se logra por intermedio de la incorporación de la distinción originaria, entre sistema y entorno, en el seno de uno de los polos, el representado por el sistema ${ }^{10}$. Como resultado de distinguir entre sistema y entorno en el interior del sistema, obtenemos a su vez la distinción, pertinente a efectos de autoobservación de las comunicaciones jurídicas, entre autorreferencia y heterorreferencia. Con posterioridad, las comunicaciones asociadas al vector autorreferencial se adensan para conformar la identidad del sistema frente al entorno, si bien conviene no olvidar que la referencia al entorno que se obtiene de esta guisa es siempre una referencia internamente construida, es una construcción interna de una realidad que se toma como externa ${ }^{11}$. En el caso del Derecho, es notorio que el entorno es siempre jurídicamente relevante o irrelevante, de acuerdo a las necesidades que ocasionalmente planteen las comunicaciones del sistema jurídico ${ }^{12}$. La atención al entorno da cuenta, precisamente, de la dimensión cognitiva de todo sistema jurídico -la responsivity a que autores como Nonnet y Selznick aluden ${ }^{13}$ - de su asimetría en relación al medio al que ha de adaptarse y presentar respuestas evolutivamente adecuadas ${ }^{14}$.

${ }^{10}$ Es lo que Spencer Brown (en Laws of Form...), a quien Luhmann debe gran parte de su cálculo autorreferencial, llama re-entry. Se trata de incorporar lo distinguido en uno de los polos de la distinción. En este caso, el entorno, como opuesto al sistema, se incorpora en éste, pero no ya para la constitución del sistema, sino para permitir su autopoiesis posterior sobre la base de la observación de la diferencia entre sistema y entorno. La diferencia entre sistema y entorno es así reproducida por el sistema como distinción entre autorreferencia y heterorreferencia. Con posterioridad, la observación de lo que se adhiere al polo de la autorreferencia permite representarse la identidad del sistema frente al entorno, y discernir sus operaciones propias frente a las que no pertenecen a su ámbito funcional. La observación, pues, es necesaria como orientación del modo de operación del sistema, para la recursión de comunicaciones, y este requerimiento funcional explica otros artefactos semánticos internamente generados, como la imputación, la acción, la culpabilidad o la persona.

${ }^{11}$ Esta es la base de la epistemología constructivista de la teoría de sistemas. No hay en ningún supuesto un contacto ni tampoco un conocimiento directo de la realidad externa a los sistemas, al margen de las comunicaciones y procesamientos de sentido que tienen lugar internamente a ellos. Las observaciones que atañen a la realidad exterior aparecen así necesariamente modeladas por los requerimientos del código, y por las demandas conectivas de las operaciones del sistema. Luhmann añade que «el punto de partida es la tesis de que un sistema autorreferencial sólo puede reproducir y crear asociaciones para sus operaciones propias sobre el fundamento de una autoobservación y autodescripción continuas» en «Recht als soziales System», pág. 8.

${ }^{12}$ En este sentido, se insiste en que es el sistema jurídico mismo el que engendra los conflictos que precisa para su evolución y el mantenimiento de su autopoiesis, y ello en razón de la necesidad de representación de la realidad con el auxilio de las distinciones de que internamente disponga.

${ }^{13}$ En su obra clásica Law and Society in Transition, London, 1978.

${ }^{14}$ No otra cosa está detrás de la preocupación luhmaniana por la «adecuación social de la dogmática jurídica». Puede verse sobre este particular, el capítulo tercero de Sistema jurídico y Dogmática jurídica. 
Las estructuras del sistema jurídico, en particular los programas normativos, se enderezan a la generación de sensibilidades específicas ante las irritaciones que se perciben del entorno, tanto interior (otros sistemas sociales) como externo (sistemas psíquicos, por ejemplo). El sistema jurídico aparece de este modo dotado de sensores específicos, de canales de irritación que se dejan alterar por variaciones determinadas que se imputan heterorreferencialmente al entorno. En los casos en que el acompasamiento es más urgente entre distintos sistemas, se llega evolutivamente a la constitución de auténticos acoplamientos estructurales, genuinos mecanismos intrasistémicos que permiten una sensibilización recíproca ante las variaciones que en cada uno de los polos sistémicos pueda tener lugar ${ }^{15}$.

Así pues, la clausura normativa va de la mano de la apertura cognitiva del sistema jurídico o, formulado de otra guisa: el Derecho está abierto a información cognitiva pero cerrado a control normativo ${ }^{16}$. La unidad del sistema jurídico como orden de comunicaciones específicamente encaminadas al cumplimiento de una función social demanda de la clausura operativa, mientras que la susceptibilidad de elaborar informaciones procedentes de su entorno psíquico o social, postula una apertura al entorno sobre el vector (interno, insisto) de la heterorreferencia ${ }^{17}$. Siendo así las cosas, lo verdaderamente determinante es el modo en que ambas dimensiones, cognitiva y normativa, resulten combinadas a través de las operaciones del sistema, lo que puede lograrse con el auxilio de diferentes recursos: dogmática adapta-

${ }^{15}$ La Constitución, o la propiedad privada, constituyen ejemplos de tales acoplamientos estructurales. En el primer caso, se trata de un acoplamiento entre el sistema jurídico y el sistema político. A través de los acoplamientos estructurales, los sistemas abren canales específicos de irritación a determinadas variaciones estructurales del entorno, con lo que se produce una rápida traducción de lo que se imputa a ese entorno particular, como información, en el interior del sistema acoplado. La coevolución que se auspicia por este cauce es más rápida y eficaz que la que se deja librada al mero azar de los contactos entre sistemas, o a la más tenue «conservation of adaptation», que supone tan sólo que los sistemas están normalmente adaptados entre sí hasta tanto las perturbaciones en el entorno alcanzan tal magnitud que el sistema resulta directamente amenazado de desaparición. Es lo que sucede, por ejemplo, en la interpenetración de los sistemas sociales y los sistemas biológicos. Nótese además que, pese a la identidad aparente de la estructura, ésta tiene un papel funcional diferente en cada uno de los sistemas acoplados, por lo que, cabalmente, no puede hablarse de coincidencias de sentido. Más información puede obtenerse, por lo que hace a los acomplamientos estructurales en general, en Die Gesellschaft der Gesellschaft, Frankfurt, Suhrkamp, 1997, págs. 776-788, y en lo relativo al caso específico del sistema jurídico y su entorno intersistémico, en Das Recht der Gesellschaft, op.cit. págs. 440-495.

${ }^{16}$ «Self-reproduction of Law and its limits», en Essays on Self-Reference, New-York, Columbia, 1990, pág. 229.

${ }^{17}$ No existe ni la necesidad ni la posibilidad de una autodeterminación completa del contenido de las decisiones jurídicas. La lógica adaptabilidad a los requerimientos de la evolución del entorno presupone la apertura como condición de supervivencia funcional. 
da a la realidad, jurisprudencia consecuencialista, cambios legislativos, programación condicional o finalista, empleo de conceptos jurídicos indeterminados y así un largo etcétera.

Esta primera precisión funcional sobre el Derecho, compartida en algún lugar por Günther Jakobs, arrastra varias predecisiones de calado, y obliga a la postergación de muchas atribuciones al funcionamiento del sistema jurídico que entretanto se han hecho clásicas. Si se sigue con una mínima atención el lento desenhebrarse del planteamiento de Luhmann, se ve a las claras cómo sus presupuestos conceptuales de partida lastran todo lo que se va decantando como resultado de la teoría. La clausura operativa, en esta línea, prohibe cualquier suerte de contacto intersistémico, cualquier transvase de comunicación entre el sistema jurídico y otras realidades que se emplazan en su entorno. El problema no es ni mucho menos baladí, y se agrava en el campo que nos toca, el Derecho penal, donde precisamente se parte de la existencia de flujos de información y control desde la periferia de los sujetos individuales, como productores de conductas desviadas, y el sistema jurídico, como provisor de respuestas comunicativas que al cabo alientan la modificación efectiva de aquéllas.

Luhmann no analiza cómo las expectativas, que se generan en gran medida individualmente, como consecuencia de los deseos o intenciones que albergan sujetos particulares, pueden traducirse en el lenguaje del Derecho, y recibir una elaboración extrapsíquica. El problema alcanza incluso el supuesto en que las expectativas rebasan el ámbito de lo psíquico, de la elaboración en sistemas que operan sobre las operaciones de la conciencia, y atañe directamente a otros sistemas sociales. A tenor de la clausura que también éstos exhiben, no se ve cómo podrían trasladarse de modo reconocible expectativas generadas y cristalizadas en el interior de un subsistema social como el de la economía, al interior del sistema jurídico. La presuposición de acoplamientos estructurales, por su parte, torna sensible a los sistemas entrelazados de cara a irritaciones específicas, los sincroniza en el tiempo y permite que las elaboraciones propias sean aprovechadas de algún modo por parte del otro sistema. Pero no parece claro cómo este acompasamiento tan tenue, que no va más allá de la sensibilidad mutua y el solapamiento temporal de acontecimientos, pudiera dar razón de la aparente reproducción que de las relevancias de un sistema se hace en el colindante.

Los heterodoxos de la teoría de sistemas han llegado a admitir la existencia de posibilidades reales de contacto, influencia y control intersistémico, o al menos la presencia incontrovertible de mecanismos de circulación de informaciones entre distintos ámbitos sociales y personales. Lo curioso es que el mismo Luhmann parece abonar tal especie de relación ampliada con relación a los expedientes arracimados en torno a la heterorreferencia 
interna, los acoplamientos estructurales, la sincronización temporal y la «conservación de la adaptación». En su última obra, Die Gesellschaft der Gesellschaft, Luhmann sugiere la posibilidad de establecer acoplamientos operativos, junto a los meramente estructurales. Sabemos ya que los últimos respetan escrupulosamente la autopoiesis de los sistemas acoplados, la construcción de la realidad de acuerdo a sus relevancias internas respectivas, y que limitan por todo ello drásticamente cualquier posibilidad de contacto y mucho menos, de influencia recíproca. No pueden atisbarse operaciones externas para el acoplamiento, ni sistemas intermediarios con una autopoiesis propia. Los acoplamientos operativos, no obstante, vendrían a alterar esas premisas de funcionamiento: en el caso de distintos sistemas $\mathbf{s o -}$ ciales -que comparten, pues, el modo operativo de clausura, las comunicaciones- cabe utilizar este fundamento autopoiético genérico para postular contactos y traducciones mutuas a una mayor celeridad que la que permiten los acoplamientos estructurales ${ }^{18}$. Los acoplamientos operativos «condensan y actualizan las irritaciones recíprocas y permiten una subsiguiente ganancia de información, de modo más rápido y mejor, en los sistemas participantes» ${ }^{19}$.

A salvo de esta última posibilidad, cuerpo extraño en la teoría del último Luhmann, y nunca desarrollada por éste, no parecen poder predicarse más posibilidades de auténtico contacto intersistémico. Al margen de estas consideraciones, quedan tan sólo las posibilidades de observación propias de cada uno de los sistemas. A través de tales observaciones los sistemas se hacen capaces de atender a las distinciones con que ellos mismos u otros sistemas operan (autoobservación, observación externa) haciendo visible lo que, en el curso de la operación básica, permanece oculto. Se accede a la contemplación, por así decirlo, de lo que no se puede ver cuando se ve ${ }^{20}$. En

\footnotetext{
${ }^{18}$ Luhmann cita los casos de sistemas políticos de negociación corporativa, y de los «círculos de conversación» en el ámbito de la industria farmacéutica sobre temas relacionados con la investigación, el Derecho de patentes, etc. Creo que esto representa una alteración sustancial de los presupuestos de constitución y funcionamiento de los sistemas sociales, sobre la base del empleo de un lenguaje reconocible por todos los actores involucrados en una interacción más o menos estable en su carácter. La misma dificultad, como veremos, está presente en la traducción de pensamientos conscientes al sistema social a través del lenguaje, en el caso de acoplamientos estructurales entre sistemas psíquicos y sociales. Pese a los intentos de Luhmann, si ha de haber intersubjetividad del reconocimiento de sentido, aquiescencia a lo elaborado por un sistema y asunción de tal significado en forma de premisa de una comunicación, ha de postularse algún género de contacto o input, lo que pondría en jaque a la autopoiesis. No otra cosa es la que critica Habermas en Faktizität und Geltung, Frankfurt, Suhrkamp, 1994, $2^{\mathrm{a}} \mathrm{ed}$, capt. 2 y la que ha propuesto Günther Teubner, en las filas sistémicas.

${ }^{19}$ Die Gesellschaft der Gesellschaft, pág. 788.

${ }^{20}$ A propósito de este desarrollo de la epistemología constructivista, remitimos al lector a los trabajos de Soziologische Aufklärung,volumen 5, Opladen, Westdeutscher, 1990, en especial, págs. 31-58.
} 
el caso del sistema jurídico, un observador externo, por ejemplo, un observador sociológico, puede establecer una relación entre las comunicaciones propias del sistema jurídico y la influencia que las mismas reciben y despliegan en el entorno, psíquico o social ${ }^{21}$. Se constata así que los sistemas operan de modo ciego en el cumplimiento de su autopoiesis, y que precisan de una observación de segundo orden ${ }^{22}$ para así poder orientar su dirección operativa, o incluso para constatar el hecho de que tales comunicaciones poseen un referente funcional de cara al sistema social general. De ahí la necesidad de las observaciones para la reproducción operativa, y de ahí la misma necesidad de asociar descripciones a los actos básicos del sistema para poder establecer el curso de las asociaciones comunicativas posteriores. Ese papel es cumplido por las acciones y por la persona, artefactos semánticos que garantizan la posibilidad de observar e imputar las comunicaciones propias del sistema ${ }^{23}$.

\section{Consecuencias dogmático-penales del planteamiento de Luhmann. Especial atención a la «paradoja del control»}

Deseo emplear el resto del artículo para esclarecer algunas de las consecuencias que se derivan de estos presupuestos epistémicos y metodológi-

${ }^{21}$ Las posibilidades de este análisis se detallan en Die soziologische Beobachtung des Rechts, Frankfurt, Alfred Metzner, 1986 y, muy recientemente, en el ensayo póstumo «Die Rückgabe des zwölften Kamels», en Zeitschrift für Rechtssoziologie, 21 (2000) H.1, págs. 360. De especial interés e importancia es contemplar en qué medida cabe una reintroducción controlada de estas observaciones en el funcionamiento operativo propio del sistema, por ejemplo, a propósito del afinamiento de las categorías dogmáticas (autoobservación del sistema) como retícula de observación y adaptación a la realidad social.

${ }^{22}$ Las observaciones son siempre operaciones, que ponen a la base una distinción propia, que por eso mismo, resulta invisibilizada, hecha latente, para el sistema que observa. Lo crucial en una mirada constructivista es ver cómo se ve, ver cómo lo necesario para la operación de un sistema se hace contingente desde la contemplación externa, que se sirve de otras relevancias. La mirada funcional y la construcción de la teoría de sistemas no son sino eso, gigantescos dispositivos de observación o mejor, autoobservación de la praxis de la sociología. por ese motivo, la teoría sociológica se termina disolviendo en una epistemología constructivista de lo social, pues en Luhmann, toda ontología está en el fondo mediatizada por la consideración del cómo de lo observado frente al qué de la observación. Las remisiones sobre esto son múltiples. Por escoger dos de ellas, reenviamos al lector a Die Wissenschaft der Gesellschaft, Frankfurt, Suhrkamp, 1990 y a su última obra de gran aliento teórico, la ya citada Die Gesellschaft der Gesellschaft. Para una introducción, me permito a lo ya dicho en otras ocasiones por este autor, en «El Derecho y la moderna Teoría de Sistemas», en La Joven Sociología jurídica en España. Aportaciones para una consolidación, J. L. Domínguez y M.A. Ramos (coord.) Oñati, IISL, 1998; y «La Teoría de Sistemas de Niklas Luhmann y el Derecho», en El Derecho en la moderna Teoría Sociológica, J. A. García Amado (ed), Dykinson-IISL, en prensa.

${ }^{23}$ También Jakobs se apercibe del carácter puramente construido de la imputación y de la gestación de la categoría de la persona en el Derecho penal, consecuencia necesaria de la comprensión del sistema jurídico como sistema de comunicaciones. Así, en Norma, persona... págs. $50 \mathrm{y} \mathrm{ss}$. 
cos de Luhmann de cara a una recta comprensión de las funciones y limitaciones del Derecho penal.

El Derecho protege, como función propia y privativa que justifica su autonomía social, expectativas normativas de conducta. Permite la extensión de éstas en la dimensión temporal, su integridad y una eventual respuesta institucional en el supuesto de su infracción. En otros lugares, Luhmann habla más bien de generalización congruente de expectativas de comportamiento en las dimensiones temporal, objetiva y social, pero lo cierto es que la normatividad alude mayormente a la primera de las referencias, al mantenimiento de las expectativas en un futuro aún incierto. Se garantizan las expectativas, y nunca la conducta conforme a tales expectativas. El Derecho no puede asumir el rol de garante de lo que esperamos, del contenido de nuestras proyecciones normativas. Protege un estilo de espera, la refractariedad al aprendizaje ante la frustración, la certeza de que nuestra expectativa es correcta a través de una comunicación de tipo especial.

El delito cumple tal requisito, en cuanto hace visible cuándo se ha obrado contrariamente a lo esperado por intermediación de una comunicación institucional. La pena, en su consideración comunicativa, sirve para individualizar el eslabón en el que se dio lugar a comunicaciones antijurídicas. Ni más ni menos que eso. El delito pone en marcha una cadena de comunicaciones que se adhieren y se despliegan sobre uno de los polos del código, el Unrecht. A partir de ahí, se conforma una historia propia, de acuerdo a las estructuras programáticas propias del sistema (normas), y a su memoria dogmática (interpretaciones), que permite arribar a una decisión final.

Es pertinente hacer notar que el delito, como comunicación antijurídica, no supone un disvalor moral que precise de reparaciones especiales en el interior del sistema jurídico. No hay, frente a lo que sostienen los partidarios de la prevención general positiva, al menos no en el seno del sistema jurídico, vulneraciones morales que hayan de ser expurgadas enérgicamente para restablecer una sana conciencia jurídica. Luhmann persigue con saña tales contaminaciones morales en el interior de sistemas ajenos a la ética. Lo relevante en la comunicación que representa el delito es tan sólo que suscita ulteriores comunicaciones en la dimensión de lo antijurídico, y que la respuesta debe atender a esta historia de la interacción ya delineada en los patrones de memoria del sistema. Que el sistema ha de ser capaz de discriminar con nitidez esta singularidad en la comunicación, poniendo en marcha una recursión especial para el caso, sin interrumpir en ningún momento su autopoiesis. Y que el valor conectivo de la comunicación antijurídica es igual a la que representa una conducta observante para el sistema. Crucial es sólo la discriminación binaria del código, el hecho de que no puede 
transitarse de lo jurídico a lo antijurídico ${ }^{24}$, que no puede aprenderse que la comunicación sobre expectativas defraudadas da lugar a respuestas en el polo de lo amparado por el Derecho, o que a la comunicación antijurídica no puede seguir en ningún caso la necesidad de aprender la desviación de modo cognitivo ${ }^{25}$.

¿Qué significado puede tener entonces, la exigencia de preservar la conciencia normativa frente al delito a través de la comunicación especial que la pena representa? A tenor de lo apuntado, únicamente que la igualdad de respuesta ha de garantizar las expectativas de los sujetos, tanto observantes cuanto infractores, y que siempre han de ponerse en condiciones de saber en qué polo de la comunicación se cristalizan las comunicaciones que sus actos representan. La confirmación normativa alcanza sólo a la recursión de comunicaciones, y nunca se extiende a efectos psicológicos externos que debieran ser estimulados en un sujeto receptor de tales mensajes. El Derecho es indiferente ante los efectos psicológicos que eventualmente pudiera desplegar en su modo de operación, ya que su función le recluye a las expectativas como comunicaciones, y sólo toma cuenta de éstas en el momento en que ingresan en su esfera de funcionamiento a través de su transformación en comunicaciones relativas a uno de los valores del código. El antes o el después de ese procesamiento puede ser en su caso observado externamente por el sociólogo, o ser recogido, drásticamente limitado, a través de las irritaciones que se imputan, heterorreferencial e internamente, al sistema psíquico, pero no constituyen ni un origen ni una meta de la autopoiesis del sistema jurídico.

Esta consecuencia de la luhmaniana «sociedad sin hombres» es una de los resultados más contraintuitivos de su teoría, y ha provocado asperezas y rechazos sin término. Los reproches de deshumanización, ceguera, pasividad o conservadurismo político tampoco se han hecho esperar, en modo alguno refrenados por la confesión del mismo Luhmann de que su propuesta no pretendería otra cosa que proteger el ámbito de la subjetividad de los em-

${ }^{24}$ Luhmann escribe que el código es, desde la perspectiva interna, una paradoja (en el caso del Derecho, que la distinción entre lo jurídico y lo antijurídico ha de pensarse como jurídica, y no como antijurídica) que ha de ser desplegada o desparadojizada por el mismo sistema en su autopoiesis (de nuevo en nuestro caso, a través de la contemplación de lo paradójico como contradictorio: lo jurídico no puede ser antijurídico). Se pasa, en palabras de Luhmann, de la paradoja de que lo jurídico lo es en virtud de lo antijurídico, a la afirmación, ya desparadojizada, de que lo antijurídico se opone a lo jurídico. Consideraciones de esta índole conforman el núcleo de su importante ensayo, ya citado, «Die Rückgabe des zwölften Kamels: zum Sinn einer soziologischen Analyse des Rechts», en especial, págs. 22-3.

${ }^{25}$ La combinación de los códigos jurídico-antijurídico, normativo-cognitivo es la que enhebra la historia de la comunicación que el delito o en su caso, la comunicación sobre comportamientos observantes, pone en marcha. 
bates furibundos de la normatividad social incontrolada ${ }^{26}$. Lo cierto es que se hace tremendamente dificultoso concebir un Derecho al margen del control o de los efectos psicofísicos que provoca en su operación, centrado de modo autista en su autopoiesis, hurtándose la mirada al mundo si no es a través del espejo de su autorreferencia. La misma perplejidad que suscita el abandono de otras funciones que se consideraban otrora connaturales al Derecho, como el control de la conducta o el logro de la integración social.

Es justo admitir que estas tareas clásicas del Derecho reingresan por la vía de la prestación (Leistung), que el sistema jurídico produce de cara a otros sistemas en su entorno. La prestación es entendida por Luhmann como «la observación de otros subsistemas en el entorno social interno (o también: de otros sistemas en el entorno externo)» ${ }^{27}$. Las prestaciones son resultado del crecimiento de la complejidad que la diferenciación funcional trae consigo, esto es, de la imposibilidad de que cada uno de los subsistemas resultantes pueda llevar a cabo cualesquiera funciones de mantenimiento y garantía de la estabilidad. La prestación apunta a la dependencia de cada sistema con relación a las prestaciones, simultáneas y complementarias, que son realizadas en otros sistemas, y a la renuncia consiguiente de la redundancia funcional ${ }^{28}$. Y en especial, refuerza la disposición a las irritaciones en el interior de los sistemas, a tornarse perceptivos ante cualquier atisbo de comunicación creada en el entorno del sistema, de cara a las que ahora se desarrollan internamente sensores y acoplamientos específicos ${ }^{29}$. En lo que afecta al Derecho penal, las interpenetraciones entre el sistema psíquico y el jurídico no pueden ser ni mucho menos postergadas, aunque

${ }^{26}$ Amén de que Luhmann cree que los sujetos reingresan en el dominio de lo social por medio de la inclusión de referencias inviduales (a título de descripción, de semántica) en todos y cada uno de los subsistemas sociales. Pero, claro está, de nuevo condicionada por los rasgos que en cada caso debieran estilizarse para satisfacer los requisitos funcionales de la autopoiesis del sistema de referencia. Habría así un homo economicus, distinto del homo juridicus, y la dificultad radicaría en delimitar la base de su unificación al margen de sus redefiniciones funcionales.

Puede observarse que no es algo muy diferente lo que subyace a la interpretación de la persona como ciudadano obediente en Jakobs, desprovista de cualquier rótulo identificador al margen de su rol de cumplimiento de normas.

${ }^{27}$ Die Gesellschaft der Gesellschaft, pág. 757.

${ }^{28}$ Luhmann caracteriza a los sistemas tanto como «dependientes de las prestaciones» de otros sistemas (Leistungsabhängig), cuanto como en disposición de rendir prestaciones a favor de esos sistemas adyacentes (Leistungsbereitschaft).

${ }^{29}$ Es lo que sucede, por ejemplo, en las relaciones entre sistema político y sistema jurídico. El último descansa en la provisión de legitimación que de que goza el sistema político, y se hace especialmente susceptible frente a las erosiones que ésta pudiera sufrir. También el sistema político se torna sensitivo frente a las formas que el Derecho adopta, y de cara a las reelaboraciones que la dogmática suministra (piénsese, por ejemplo, en la importancia que adquieren las interpretaciones de principios constitucionales, sin ir más lejos). 
los efectos psíquicos y de control hayan de quedar al margen de la mirada funcional del Derecho.

Lo característico de las funciones, frente a las prestaciones, es la ausencia de equivalentes sistémicos de cara a su satisfacción. Así, la función de garantía de expectativas normativas de comportamiento es algo que sólo al Derecho compete, y no puede en modo alguno venir servida, ni siquiera a título derivativo o parcial, por ningún otro subsistema de la sociedad. Y sin embargo, con las prestaciones sucede justo lo opuesto: pueden buscarse equivalentes funcionales a la realización de una prestación por parte de cualquier sistema. Las funciones jurídicas de control de la conducta se encuentran precisamente en esta tesitura: pueden ser perfectamente reemplazadas por la operación de otros sistemas. Pensemos en el sistema de la educación, con su generación de susceptibilidades de obediencia individual, o en el sistema político, en la medida en que absorbe competencias de dirección de la conducta o resolución de conflictos.

La perspectiva funcional del control es sobremanera significativa en la discusión de las teorías penales de la prevención, ya sea ésta positiva o negativa. Lo que caracteriza a la primera frente a la segunda es, sin lugar a dudas, una apertura a la generación de influencias sobre la conducta de un modo refinado y rico en perspectivas, frente a la linealidad y adustez de la prevención negativa, que fía demasiado a los mecanismos de la coacción y la disuasión que el empleo de la fuerza representa. Sin embargo, lo que ahora nos importa resaltar en colores vivos es el hecho, incontrovertible desde el enfoque sistémico, de que el control, en cualquiera de sus manifestaciones $\mathrm{y}$ virtualidades, no pertenece como tal al dominio funcional del sistema jurídico, y que no puede, por eso mismo, ser alentado como una función propia y definitoria de lo normativo ${ }^{30}$. El Derecho, en Luhmann, ha de conformarse con lo que puede cabalmente garantizar en su operación: el mantenimiento de las expectativas ante la decepción, y esa refractariedad viene servida, en la mayoría de los casos, por una abierta y manifiesta indiferencia frente a los actos de desviación de la conducta, frente a lo antijurídico ${ }^{31}$. El

\footnotetext{
${ }^{30}$ Recojo por su contundencia la afirmación con que se despacha en su escrito póstumo «Die Rückgabe...», pág. 31: «...el control tan sólo es control, entendido como la comparación del presente con el pasado, pero no cotejo del presente con el futuro. Precisamente, el incremento de la capacidad de control hace patente que las posibilidades de una conformación planificada del futuro no puede encontrar sustento alguno. Para ello se requeriría una comparación entre input y output que el control no puede ciertamente proporcionar». Por el mismo motivo, toda regulación es, necesariamente, autorregulación.

${ }^{31}$ Reproche que amplía Baratta a las teorías de la prevención positiva. Alessandro Baratta, «Integración-Prevención: una «nueva» fundamentación de la pena dentro de la teoría sistémica», en Cuadernos de Política Criminal, 1984, pág. 548. El artículo de Baratta sigue conservando plena vigencia en los reproches que dirige a la teoría de sistemas, pero también en las
} 
impacto del futuro, incierto en sus exigencias y en los cursos que adopta, ha de ser aminorado, pues la complejidad que traería consigo un intento, siquiera atenuado, de predecir las consecuencias de las acciones, multiplicaría la complejidad determinable allende los límites y capacidades del sistema. Tal inmunización simbólica del Derecho frente a las decepciones es la que, en consecuencia, nos permite mantener nuestras formulaciones de expectativas y la integridad de las normas que sobre ellas se enraizan ${ }^{32}$.

Luhmann, pese a la contundencia con que asimila el sistema jurídico a la protección de expectativas, es perfectamente consciente de que no puede postergarse sin más la consideración del control o influencia de las conductas efectivas que toda norma alienta, con lo que se ve forzado, más allá de las constricciones funcionales de su teoría - un sistema, una función - a dotar de un espacio propio para la observación de lo que efectivamente acaece en la vida social de la expectativa. Conviene advertir que la perspectiva de control a la que se atiende es exigüa en su alcance: sólo la que tiene como objeto expectativas dañadas en su integridad. Con tal limitación, el Derecho se ve remitido a un trato reactivo con los conflictos, lejos de toda pretensión de planificación, que cae del lado de otros sistemas sociales (singularmente, el político). El futuro reaparece así en conexión con la memoria del sistema, con sus estructuras normativas, que son las que al cabo determinan su vigencia limitada a los supuestos almacenados en las expectativas cristalizadas.

Si bien la perspectiva temporal accede al primer plano de la reflexión de Luhmann, como amenaza principal de complejidad, conviene no dejar precipitadamente de lado las inseguridades que engrosan otras dos formas de contingencia: la objetiva y la social. Así, la proliferación de interpretaciones divergentes y a menudo contradictorias de las expectativas, irreductible en demasiadas ocasiones por vía dogmática o con el expediente tajante de la decisión ${ }^{33}$, y el fenómeno inabarcable de la doble contingencia y de la ex-

posibilidades entrevistas en el planteamiento funcionalista del primer Luhmann, y no movilizados por las teorías de la prevención positiva.

${ }^{32}$ El tema de la trivialización simbólica de las desviaciones cumple un papel sistemático de primer orden en la reflexión jurídica de Luhmann, y ha sido objeto de trato recurrente desde su Rechtssoziologie. Más recientemente, pueden leerse las consideraciones vertidas en los artículos consagrados a la delimitación funcional del Derecho en Ausdifferenzierung des Rechts, págs. 73-91 y Das Recht der Gesellschaft, págs. 124-164.

${ }^{33}$ Luhmann reitera la necesidad de consolidar la consistencia objetiva de las decisiones como medida para conjurar la complejidad que implicaría una dispersión inabarcable a la mirada entrenada del jurista. La dogmática ha de erigirse en garante de una mínima igualdad interpretativa, y esa congruencia en las respuestas interpretativas es la que está a la postre tras la relectura de la justicia y la que hace avanzar la adecuación social de la dogmática. 
pansión de los contactos intersubjetivos a escala planetaria representan sendas amenazas a las ínfulas de control jurídico de las conductas.

El control vendría a colmar el desideratum de apertura de todo sistema jurídico, como opuesta a la clausura operativa que la recursividad de comunicaciones normativas vendría a representar. El sistema jurídico se asimetriza a través de las funciones y las prestaciones que ha de cumplir, se abre -bien que informacionalmente- de cara a su entorno, lo que delata la tensión inherente al planteamiento luhmaniano, entendido en su pureza radical. Pues la función, conviene tenerlo presente, es siempre función social, función de cara al entorno, con todo lo que esta idea arrastra de posibilidad de comunicaciones y tareas puestas en común, y repartidas entre sistemas. La asimetría que el sistema crea ha de incorporar, a mi entender, algo más que el despliegue de las posibilidades de observación del sistema con arreglo a observaciones de segundo orden, a través del vector de la referencia externa. Parece plausible el mantener el carácter primariamente interno del tratamiento de las comunicaciones y la reconstrucción particular de las interacciones y conflictos en el seno de cada sistema de referencia. Pero el vedar, junto con ello, cualquier susceptibilidad de influencia desde y sobre el entorno exterior, cualquier atisbo de comunicación compartida y trasladada, al margen de los acoplamientos estructurales ${ }^{34}$, parece forzar el planteamiento hasta extremos en que la misma orientación funcional y el discurso sobre las prestaciones carecería de auténtica plausibilidad explicativa.

Lo cierto es que el discurso del normativismo, entendido como contrafacticidad de las expectativas, está preñado de dificultades para comprender exigentemente la contingencia modal que el futuro nos trae. Parece insuficiente tratar de cerrarlo en falso sobre la disyunción entre los polos de la juridicidad y la desviación antijurídica, como se plantea desde la autopoiesis del Derecho. El rechazo del consecuencialismo veda otras opciones, por su incompatibilidad con la rigidez del planteamiento teórico. La cuestión es la

${ }^{34}$ La necesidad de reconstruir internamente lo que se recibe por vía de acoplamiento refuerza la sospecha de que nos movemos circularmente en torno a las seducciones del solipsismo, todo lo refinado que se quiera. El acoplamiento no permite contacto alguno, sino mera irritabilidad reforzada, mera atención a lo que tiene lugar sincronizadamente en un lugar del entorno topológico, en medio del ruido generalizado de las comunicaciones que tienen lugar en otros sistemas. La comunidad de sentido entre los rendimientos cognitivos de los sistemas acoplados no se logra, aún cuando algunas sugerencias, relativas al papel del lenguaje o del sentido como rendimiento reductor de la complejidad común a sistemas psíquicos y sociales pudieran hacer sospechar lo contrario. Lo mismo que sucede con los acoplamientos operativos a que hice mención más arriba. Creo que las coacciones que la autopoiesis como opción de partida plantean impiden que Luhmann se atreva a ir más lejos. Lo que no ha sido obstáculo para que otros autores de filiación sistémica transiten otras vías. Por todos, el artículo conjunto de Willke y Teubner, «Kontext und Autonomie: gesellschaftliche Selbststeuerung durch reflexives Recht», Zeitschrift für Rechtssoziologie 6, n.4, 1984. 
de si una sociedad funcionalmente diferenciada y en rápida transformación puede permitirse una forma tan rudimentaria de trato con la complejidad desbordante que un futuro abierto imprime. La multiplicidad de cursos posibles y alternativos de acción y de vivencia parecen vedar cualquier posibilidad de respuesta puntual al entorno, por lo que se demandan nuevas formas de elaboración de las informaciones. La necesidad de responder adaptativamente, de iniciar procesos de aprendizaje ante lo novedoso ${ }^{35}$, nos ponen ante los ojos la duda de si el Derecho podrá seguir contando, en la misma medida en que lo ha venido haciendo, como expediente de reducción y manejo de la complejidad social, en sus vertientes objetiva, social y temporal.

Luhmann no ha ignorado la dificultad de fondo que la paradoja del control pone sobre el tapete: éste es al mismo tiempo más complejo, y más perentorio. Las soluciones internas al funcionamiento autopoiético de los sistemas, tales como la observación externa sobre la heterorreferencia, las irritaciones y aperturas informacionales al entorno, los acoplamientos estructurales, etc. parecen haberse revelado como claramente insatisfactorias, al menos desde mi modesta perspectiva. Otras soluciones planteadas han venido de la mano de una supuesta diferenciación interna, a efectos de la competencia de la elaboración de comunicaciones, entre las instancias legislativas y las judiciales. A las primeras correspondería una orientación más netamente consecuencialista, abierta a las transformaciones del entorno social y externo, mientras que los decisores judiciales habrían de encargarse de las correcciones que vulneraran el tenor de la normatividad cristalizada en las estructuras. El problema recae de nuevo en la definición de la unidad del sistema sobre la reproducción de la normatividad, y atañe a la concepción razonable de los límites a la apertura al entorno. En última instancia, una orientación consecuencialista parece amenazar con desdibujar los límites que se trazan entre los sistemas político y jurídico, lo que no parece preocupante de ordinario, pero sí es potencialmente destructivo en un planteamiento como el de Luhmann.

Más problemas plantea otra de las soluciones apuntadas por Luhmann, tanto por su endeblez como por sus riesgos antidemocráticos. En algún lugar, Luhmann plantea que podría reservarse un trato cognitivo con los acontecimientos a las instancias encargadas de la decisión jurídica, cerrando tal elaboración a los destinatarios últimos de las decisiones, la ciudadanía. El juez podría así ver ampliado su radio de acción, lo que parece compadecerse bien con el nuevo estilo dogmático y con los instrumentos legislativos

\footnotetext{
${ }^{35}$ El problema del sentido positivo de las desviaciones, de lo que, en términos cibernéticos se conoce como «retroalimentación positiva» se compadece mal con un estilo puramente normativo de expectativa.
} 
que se ponen a su servicio (cláusulas generales, conceptos jurídicos indeterminados, legislación finalista, etc.), colindante ahora con el reconocido al legislador. El ciudadano usuario del Derecho obtendría, cínicamente, la ventaja de saber que sus expectativas mantendrán su estabilidad a lo largo del tiempo y que no sufrirán modificaciones ni manejos arbitrarios como precio por mantenerse en su desnuda afirmación.

El condicionamiento ${ }^{36}$ es otra de las perspectivas que se plantean para dar entrada a la consideración activa del entorno en el interior del sistema. Este mecanismo permitiría que las normas y las decisiones internas al sistema se pusieran en marcha únicamente si llega a constatarse la aparición de determinados acontecimientos imputados al entorno. De nuevo, la reserva se establece sobre el hecho de que, primero, la percepción es percepción internamente modelada, ajustada a los criterios de relevancia cognitiva del sistema, y en razón de lo que podríamos llamar principio de conservación de la autopoiesis. Esto es, el condicionamiento nunca podría vulnerar el sentido de la reproducción de las comunicaciones, ni violar las previsiones estructurales, ni facilitar un cruce ${ }^{37}$ entre los polos del código básico del sistema. Esta propuesta, encaminada a la combinación de normas y cogniciones en el interior del sistema jurídico, parece de nuevo quedarse demasiado corta en su aspiraciones de flexibilizar el estilo de las expectativas que conforman el núcleo del Derecho.

Quizás la salida más promisoria al dilema del control sea la que viene de la mano de las colaboraciones intersistémicas, posibilidad ésta que Luhman no proscribe, pero que limita drásticamente. El terreno infranqueable es de nuevo el relativo a la función central del sistema, que no admite equivalentes funcionales más allá de sus límites. Los sistemas, en lo que a esta orientación fundamental atañe, son órdenes autosustitutivos, y sólo pueden proveer alternativas desde las posibilidades que ya les son inherentes ${ }^{38}$. El Derecho podría, en esta línea, indagar posibilidades de sustituir a las sanciones como medio de garantía de expectativas, dando entrada a otros remedios institucionales menos gravosos para los destinatarios ${ }^{39}$.

\footnotetext{
${ }^{36}$ Sobre el condicionamiento, Soziale Systeme, págs. 44-5 y «Self-reproduction of Law and its limits», pág. 234.

${ }^{37}$ «Crossing» en el sentido de Spencer Brown, de tránsito de uno a otro valor del código.

${ }^{38}$ En relación con la autosustitución, nos remitimos a las consideraciones dispersas y fragmentarias en «Self-reproduction...», págs. 236-7.

${ }^{39}$ Otras propuestas, en la línea del «continuo de materialidad» entre el sistema psíquico y el social, avalado por el estilo reductivo de la complejidad compartido (sentido) y por la aludida «conservación de la adaptación», no pueden ser detalladas aquí. Tampoco puedo desplegar las consideraciones relativas a las posibilidades y limitaciones de las interpenetraciones entre ambos sistemas, que ponen en evidencia las incongruencias a que se ve abocado un planteamiento tan rígido como el de la autopoiesis para garantizar un mínimo contacto intersistémico,
} 
La última de las respuestas a la posibilidad de control es la más genuinamente luhmaniana: la comprensión del Derecho como «sistema inmunitario». Toda vez que hemos arribado a la irremediable conclusión de que no pueden darse contactos intersistémicos, y de que el Derecho no puede reproducir internamente la plétora de acontecimientos y posibilidades que proliferan en el entorno, le resta tan sólo hacer un uso inteligente de su memoria sistémica para desplegar patrones de respuesta aproximada ante «infecciones» del medio. Los anticuerpos (estructuras) de que dispone se movilizarían así, por medios dogmáticos principalmente, con el fin de asimilar (fagocitar) aquellos casos en que la estabilidad de la autopoiesis del sistema se viera amenazada. La correlación puntual se reemplaza así por la similitud reproducida internamente, con lo que la argumentación, en tanto aminora el efecto de sorpresa que toda novedad invoca, constituye el mejor expediente para la generación de la tranquilizadora redundancia ${ }^{40}$.

En resumen, no parece que puedan abrirse demasiadas perspectivas sin vulnerar, siquiera tenuemente, las constricciones que impone la clausura autopoiética y el solipsismo consiguiente a que se ven irremisiblemente arrojados los sistemas en su trato recíproco. Y con este lastre, epistemológico a la par que interaccional, ni hay influencia, ni tan siquiera lo que pudiera reconocerse como un diálogo.

\section{Recapitulación: posibilidades del sistemismo para la teoría de la prevención general positiva}

Hora es ya de comenzar nuestra recapitulación, reconduciendo las reflexiones apuntadas a modo de esbozo al campo de la reflexión penal. La teoría de sistemas, en primer término, plantea una redefinición de las funciones y de las categorías de la dogmática penal de tal calado que albergo serias dudas sobre la oportunidad de su apropiación. El adelgazamiento funcional del Derecho como sistema, a la resolución de conflictos de expectativas por la vía de su reafirmación, y la indiferencia del sistema jurídico ante las repercusiones en la esfera psíco-física de sus prestaciones de control, muy atemperadas por su parte, constituye una dificultad de gran magnitud, casi decisiva. El catálogo jakobsiano de funciones de la pena se estilizaría hasta casi la desaparición, cuando no se torna trivial, tras una relectura en clave luhmaniana de estricta observancia.

al menos para garantizar una unidad de referencia entre lo que se piensa (cognición, pensamiento) y su correlato comunicativo en el sistema social. Soziale Systeme, Frankfurt, Suhrkamp, 1984, capt. 6, págs. 286 y ss.

${ }^{40}$ Das Recht der Gesellschaft, págs. 338-406. 
Jakobs entiende su propuesta teórica, la prevención general positiva, como ejercicio de reconocimiento de la norma, a través una dimensión trimembre: ejercicio en la confianza en la norma, en tanto que todos los hombres son destinatarios de las normas y deberían por eso mismo conocer si pueden tener expectativas o no; ejercicio de fidelidad en el Derecho, dado que la pena persigue que el delito no se erija en alternativa de conducta susceptible de aprendizaje, y, finalmente, ejercicio de aceptación de las consecuencias, pues con la pena se aprende la conexión entre la conducta y el deber correlativo de soportar sus $\operatorname{costes}^{41}$, que a través de la pena se logra, frente a la amenaza de la fidelidad y la confianza en el Derecho que el delito plantea. Desde la perspectiva de la norma, el ordenamiento jurídico resulta preservado y fortalecido mediante la imposición de las sanciones penales en el caso de violaciones normativas. No otra cosa ha de entenderse tras el principio de conservación del Derecho, o de defensa del ordenamiento jurídico. Por último, desde la perspectiva de la sociedad que pune, la pena alienta una función de pacificación de la conciencia social ${ }^{42}$.

El Derecho penal, y la pena que se constituye en su instrumento privilegiado, cumplirían así funciones diversas, si bien íntimamente entrelazadas, a la luz de las referencias subjetivas a que se dirigen. Así, con relación al ciudadano, destinatario de las normas, el Derecho penal persigue la gestación de una conciencia fiel al Derecho, a través del efecto de socialización

La confianza en la norma adquiere nuevos contornos, al verse despojada de toda finalidad socializatoria. Ni cabe pedagogía a través del Derecho, pues eso rebasa en mucho sus competencias funcionales, ni puede alentarse una conciencia fiel al mismo. La fidelidad se retraduce exclusivamente en la confianza de que la expectativa goza de respaldo institucional, y la pena, no representa otra cosa que una comunicación de que el individuo esperó correctamente, y de que el Derecho se lo hace saber a costa del infractor. La pena, al igual que el delito, se entienden como comunicaciones, asociadas y proseguidas sobre el polo de lo antijurídico. Pero no acarrean, como piensa Jakobs en clave hegeliana, disvalor moral o socializatorio alguno, al menos, ningún disvalor que pueda ser reputado relevante en la esfera de lo jurídico. La irrelevancia sistémica de los efectos psicofísicos que el Derecho comporta se ve así añadida a la indiferencia moral de las comunicaciones jurídicas. Luhmann no pretende con ello negar cualquier posibilidad de asociación de tales efectos y enjuiciamientos a las decisiones y argumentos

\footnotetext{
${ }^{41}$ Puede encontrarse el desglose de este planteamiento en su obra clásica Strafrecht. All-

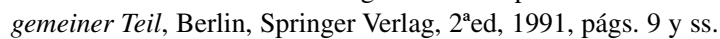

${ }^{42}$ Un análisis detallado es el que expone Pérez Manzano, en su obra citada, págs. 18 y 21-23.
} 
del Derecho por parte de un observador externo, sino únicamente advertir de su marginalidad en la mirada interna que el Derecho se dirige.

Pena y delito son dos momentos de la comunicación, y pertenecen, en sentido propio, a la autodescripción que ésta practica sobre sí misma para guiar su autopoiesis, su prosecución asociativa. Los delitos, en cuanto comunicaciones antijurídicas, son discriminados en su valor conectivo propio, con lo que inauguran una secuencia de acontecimientos que no puede ser revertida ni vuelta hacia lo jurídico. De esto se derivan ciertamente efectos de cara a los individuos, en la medida en que les permiten garantizarse una seguridad de orientación, pero de nuevo esto parece extirparse del Derecho ${ }^{43}$.

Las autodescripciones y autoobservaciones son inderogables para el funcionamiento guiado de la autopoiesis, pero eso no consolida sin más la primacía de las que el delito y la pena representan. El Derecho puede recurrir a otros equivalentes funcionales, a otros modos de autoentendimiento sin que sufra menoscabo en sus virtualidades operativas, en su funcionamiento eficaz.

Por lo que hace a la integridad del Derecho que se busca preservar a través de la imposición de sanciones, tampoco la teoría de sistemas permite una lectura como la que Jakobs tiene en mente. La integridad por la que éste apuesta es de tipo, si se me permite, hegeliano o durkheimiano: la integridad jurídica entendida como signo sensible de la fortaleza del tejido moral, de la identidad social en un sentido normativo, fuerte. En Luhmann, recuérdese, la normatividad es pura facticidad sociológica (contrafacticidad, en este caso). No existen imágenes de perfección que puedan y deban ser eventualmente alentadas desde el Derecho. Ni cabe tampoco representarse una identidad como trama subjetiva que gesta un sentido e interpreta la biografía, que sirve de base a autocomprensiones y auspicia proyecciones colectivas. La identidad es tan sólo una observación de tercer orden: la observación de lo que se condensa, en forma de comunicación repetida, en el polo autorreferencial; lo que el sistema se imputa a sí mismo con continuidad (temporal) y contigüidad (espacial). Ni más ni menos que eso. La deriva hegeliana del último (o quizás sólo penúltimo) Jakobs parece dar cuenta de es-

\footnotetext{
${ }^{43}$ No veo cómo podría hacerse esto razonablemente, si es que deseamos seguir hablando de una orientación funcional de los sistemas sociales. Para evitar todo antropomorfismo «vetero-europeo» (alt-europäisch, descalificación favorita de Luhmann con relación al pensamiento social anterior), habría que comenzar reconsiderando el empleo de vocablos como vivencia o expectativa en la teoría de sistemas o, más profundamente, redefiniendo la categoría del sentido en términos menos marcadamente fenomenológicos.
} 
ta intuición, así como la precipitación con la que se excusa por adherir, aunque sea a modo de metáfora, categorías sistémicas ${ }^{44}$.

Algo similar ocurre en el discurso sobre la estabilidad, que auspiciaría la aplicación correcta de penas ante desviaciones de conducta lesivas. La estabilidad, en Luhmann, es pura estabilidad autopoiética, la simple reproducibilidad sin cesuras temporales de las operaciones del sistema. Y, por último, similar advertencia cabe a propósito de la confianza ${ }^{45}$, mero expediente para la reducción de la complejidad social y que deriva, no del aseguramiento de un comportamiento conforme, o del resarcimiento o restablecimiento del estatus normativo tras la infracción, sino únicamente del cumplimiento cabal de la función de garantía de las expectativas. Justo es añadir, no obstante, que un incumplimiento masivo no se compadece con la función garante del Derecho, que es lo que al cabo, explica la presencia de la sanción junto a las expectativas formuladas ${ }^{46}$. La sanción, no obstante lo anterior, debe entenderse fundamentalmente en clave comunicativa, como declaración de que se ha frustrado una expectativa y de que el conflicto se resuelve a costa del sujeto responsable. Con su concurso, el riesgo de decepción resulta aminorado, pero no sobre el control del comportamiento desviado, sino sobre la mera garantía de las expectativas $^{47}$.

Podríamos seguir desglosando imposibilidades y restricciones que derivan de un esquema conceptual y metodológico tan inflexible y exigente como el de Luhmann. No obstante, las dificultades han de retrotraerse al fondo de la propuesta teórica que el sistemismo alberga, a su constructivismo epistémico, a las coacciones ontológicas de que parte, y a la rigidez del principio autopoiético de construcción de lo social. En suma, ni Luhmann es la respuesta a las exigencias de control del Derecho penal, ni su teoría

${ }^{44}$ En el prólogo de Norma, persona y sociedad en una teoría de un Derecho penal funcional, pág. 16, Jakobs se preocupa por advertir que pese a la cercanía de algunas de las categorías empleadas a la teoría de sistemas de Niklas Luhmann, «...un conocimiento superficial de esta teoría permite advertir rápidamente que las presentes consideraciones no son en absoluto consecuentes con dicha teoría, y ello ni tan siquiera en lo que se refiere a todas las cuestiones fundamentales». Y, sin embargo, la cercanía o hasta la abierta coincidencia con Luhmann son, en algunos lugares, mayores de lo que al mismo Jakobs sin duda le resultaría cómodo. Así ocurre en su concepción comunicativa de la pena o de la persona.

${ }^{45}$ El tratamiento exhaustivo de la confianza, como mecanismo de reducción de la complejidad social, en la monografía homónima Vertrauen. Ein Mechanismus zur Reduktion sozialer Komplexität, Stuttgart, Enke, $3^{\mathrm{a}} \mathrm{ed}, 1989$, en especial los capítulos 1, 5 y 7.

${ }^{46}$ Luhmann lo advierte a propósito del mantenimiento de la confianza sistémica, en Vertrauen, pág. 62.

${ }^{47}$ En Rechtssoziologie, pág. 43. 
puede dar cabida ilimitada a las intuiciones teóricas de un planteamiento tan polícromo como el de la prevención general positiva ${ }^{48}$.

${ }^{48}$ En la actualidad, preparo un trabajo, en el marco de un libro colectivo, sobre las bases sociológicas del pensamiento penal de Jakobs, que verá la luz el próximo año. A él me remito para consideraciones más exhaustivas y de mayor enjundia. 